\title{
Causes of village chicken mortality and interventions by farmers in Ada'a District, Ethiopia
}

\author{
Selam M. ${ }^{1 \star}$ and Kelay B. ${ }^{2}$ \\ ${ }^{1}$ College of Veterinary Medicine and Agriculture, P. O. Box 34, Addis Ababa University, Ethiopia. \\ ${ }^{2}$ National Livestock Consultant, FAOET DRRU, Awash Field Office, Awash, Ethiopia.
}

Accepted 16 May, 2013

\begin{abstract}
The research was conducted in Ada'a district of the Eastern Shoa Zone, Ethiopia. This study was undertaken to investigate the major causes of chicken mortality under village production system and the intervention measures by farmers against the major causes of chicken mortality under village conditions. Data were collected through structured questionnaire from 180 households. Simple random sampling method was used to select the peasant associations and the households. The majority of the respondents put predation (91.9\%) and disease (86.4\%) as major causes of mortality in chicken older than 7 days. More than half of hatched chicks are lost due to mismanagement $(29.4 \%)$, predation $(67.8 \%)$ and other causes were also mentioned by less than $10 \%$ of the respondents. Significant proportion of the respondents $(\mathbf{4 8 . 3 \% )}$ did not provide modern medicine and those using, utilize mainly broad spectrum medicines without consulting veterinarians. The traditional medicaments included different medicinal plant species. As a conclusion, chicken in the study areas are highly affected by mortality due to predation and diseases. Appropriate management should be taken, therefore, to control the incidence of disease and reduce the loss of chicken kept under village chicken production systems due to predation and mismanagement.
\end{abstract}

Key words: Chicken, disease, loss, mismanagement, predation, village.

\section{INTRODUCTION}

In many countries of the world, poultry are kept as scavengers in and around the residence areas at village and family level (Kitalyi, 1998). With an estimated total population of 1.6 billion at the end of 2010, village chicken is the most abundant species in Africa, contributing a significant part of the continents economy (FAOSAT, 2012). Under circumstances of extreme poverty where people cannot keep larger species of livestock due to shortage of land and capital, village chicken provide high quality animal protein at the source of production and income for household activities such as education, health and clothes (Copland and Alders, 2005). These benefits from family poultry production go directly to the rural poor, in most cases to the women being most active as caretakers (Gueye, 1998). In addition, chickens are also important for diversifying agricultural production and increasing household food security directly to the rural poor community, including increased distribution of resources through involvement of women (Gueye, 1998; Kitalyi, 1998). In Ethiopia, there are different ecotypes of chicken that fit or adapt to different agro-ecological regions in the country. Poultry

*Corresponding author. E-mail: meseretselam@gmail.com, peacebase2000@yahoo.com. Tel: +251-9-11-1097-03. 
population in Ethiopia at around 40.6 million with native chicken of none descriptive breeds representing $96.6 \%$, hybrid chicken $0.55 \%$ and exotic breeds of chickens mainly kept in urban and peri-urban areas $2.84 \%$ (CSA, 2009 ). From the total population of chicken in Ethiopia, $99 \%$ are raised under the traditional backyard system of management, while $1 \%$ is under intensive management system (Tadelle et al., 2003a; Ashenafi and Eshetu, 2004). The traditional poultry production system is characterized by minimal human involvement, with birds scavenging in the backyard for food and no investments beyond the cost of local grain and possibly simple nightshades. This system is also characterized by high mortality caused by factors such as disease, predators, and poor management and nutrition

In Ethiopia, the contribution of village chickens to farm household and rural economies is not proportional to their high numbers, although they contribute more than $98 \%$ of the total meat and egg production in the country (Tadelle, 1996; Udo et al., 2006). This is mainly due to low productivity levels which are the result of diseases, poor management in terms of feeding and housing, poor growth rates, predation and lack of organized markets. From these constraints, the most important are parasitic and infectious diseases and poor housing conditions, which expose birds for predation (Tadesse, 2005).

Although village chicken production is important in Ethiopia, previous studies on chicken in Ethiopia focused on commercial and state farms and those few studies done on village chicken have not been dealing with causes of chicken mortality. Understanding the different causes of chicken mortality and their relative importance is one of the pre-requisites in developing successful poultry production strategies. Therefore, the objective of this study was to investigate the major causes of chicken mortality and the intervention measures by farmers against the major causes of chicken mortality under village chicken production system.

\section{MATERIALS AND METHODS}

\section{Description of the study District}

The study was conducted at Ada'a District, which is one of the districts in East Shoa Zone of Oromiya Region. The District covers an area of $92,751.33$ ha. Debre Zeit is the town of the study district, located at $47 \mathrm{~km}$ South East of Addis Ababa with a human population of about 95,000. The average altitude is about 1880 meter above sea level. It is an important small town where many governmental institutions, national and international research centers are found. The average annual rainfall is about $839 \mathrm{~mm}$ and the average temperature is $24^{\circ} \mathrm{C}$. The District has a village poultry population of 24045 (ONRS, 2011). The soil and climate are similar to many highlands in Ethiopia.

\section{Study population}

The chicken population in the district managed under village chicken production system and farmers keeping the chicken were the study population.

\section{Study design}

A retrospective and cross sectional types of studies were carried out to investigate the major causes of chicken mortality and intervention measures by farmers against the major causes of chicken mortality under village chicken production system.

\section{Sampling procedure}

Six peasant associations (PA) were selected randomly from the district. Then, a fresh list of farm households were prepared jointly with the community representatives, village leaders, village elders and the development agents working in the selected PA's. Finally, simple random sampling techniques were employed to select 30 households from each PA, which made a total of 180 households. All poultry in a farm household were sampled as a cluster. With the national average flock size of 4.1 in 2003 (CACC, 2003) approximately a total of 738 chickens were included in the study.

\section{Data collection}

A single-visit formal survey method (ILCA, 1990) was followed to gather the necessary information. Prior to the actual survey, visits were made to the district and secondary information relevant to the study was gathered from all possible sources. The study regarding causes of village chicken mortality and intervention by farmers was undertaken using structured questionnaire.

A structured questionnaire were prepared and interview was carried out to collect data on chicken flock size and composition, chicken flock dynamics, annual chicken mortality pattern (distribution among the different groups of chicken and seasons), major causes of chicken mortality and intervention measures by farmers (strategies used to avoid mortalities and control measures employed to control mortalities).

\section{Data analysis}

The collected household data were summarized and analyzed using SPSS 16.0.1. Descriptive statistics such as mean, percentage and standard deviations were used to present the household survey results.

\section{RESULTS}

\section{Chicken flock composition and dynamics}

The overall flock size per smallholder household was 9.17 ( \pm 7.72$)$. Most of the respondents owned local breed and while few households kept exotic and hybrid type of chickens. In the overall chicken flock, hens (39.91\%) and pullets $(35.66 \%)$ comprised significant proportion. The same was true in the hybrid and local chicken flock.

The respondents indicated that the number of chicken added to the farm during the past year (2007) was low $(10.83 \pm 80.38)$ compared to the disposal rate $(32.97 \pm$ 217.56). The higher disposal of chicken was in relation to mismanagement $(29.4 \%)$, disease (86.4\%), predation $(91.9 \%)$, bad weather $(6.1 \%)$ and sell and slaughter 


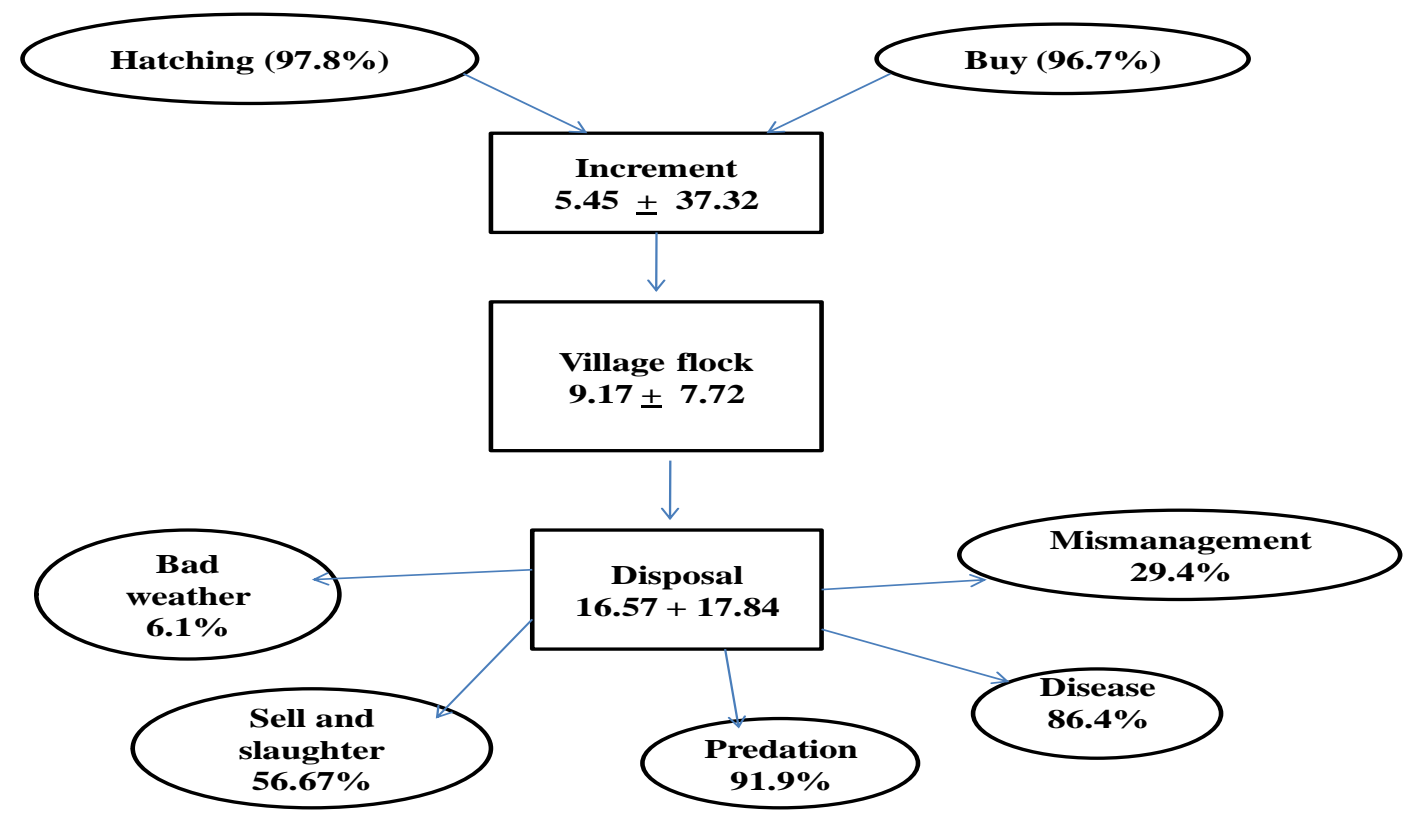

Figure 1. Chicken flock dynamics and major causes of additions and disposals of chicken from the flock.

(56.67\%) according to the respondents. Disease and predation contribute the higher proportion for the higher rate of disposal of chickens (Figure 1).

\section{Mortality of chicken}

The majority of the respondents put predation (91.9\%) and disease (86.4\%) as major causes of mortality in chicken older than 7 days. In addition, mismanagement $(0.6 \%)$ and bad weather $(0.6 \%)$ was also mentioned by some people as causes of chicken mortality (Table 1). About $50.6 \% \quad(n=91)$ of the respondents indicated that more than half of hatched chicks are lost. There were different causes for loss of new hatched chicks indicated by the respondents. More than one fourth of the respondents $(29.4 \%)$ indicated that mismanagement lead to loss of young chicks. These include water shortage and tramping by adult chicken, children and cattle. More than half of the sampled households mentioned predation as the major causes of chick mortality $(67.8 \%)$. Other causes were also mentioned by less than $10 \%$ of the respondents (Table 2). There were also different symptoms and specific diseases mentioned by the respondents that lead to death (Table 3). Most of the respondents were not familiar with the names of diseases but Newcastle disease (NCD) locally known as "Fengel" was commonly known in the study area (72.2\%). Mites were mentioned by name by some of the respondents $(11.1 \%)$ as causes of mortality in the study areas. The most important signs of diseases mentioned by the respondents were diarrhea $(65.6 \%)$, depression and death within few days (48.6\%) and lowering of the head down (28.9\%). Other signs mentioned include blackening of comb, swelling and blinding of eye, coughing and sneezing, loss of appetite and staggering movement. According to most of the respondents, disease occurrence was higher at short and long rainy season $(77.8 \%)(n=140)$. However, there were also respondents who experienced high rate of disease occurrence any time in a year $(16.7 \%)(n=30)$ and in the dry season $(5.6 \%)(n=10)$. Among the predators mentioned by the respondents, domestic cats $(71.1 \%)$, vultures $(65 \%)$ and mongoose $(42.8 \%)$ were the most important ones. In addition, dogs, wild cat, rats and birds other than vultures were also incriminated in predation of chicken. Vultures, cat, rats and other birds pray mainly chicks, while mongoose and wild cat pray all age groups (Table 4). The majority of the respondents agreed that there is no seasonal variation on the predators $(93.3 \%)(n=168)$. Those who believe in the seasonal variation in predation indicated that vultures are more common during the dry season while the predation by mongoose increased at the end of the rainy season

\section{Interventions to reduce chicken mortality}

\section{Disease control}

Of the total respondents, $48.3 \%(n=87)$ did not provide modern medicine and those using utilize mainly broad spectrum medicines without consulting veterinarians. On the other hand about $80 \%$ of the households used traditional medicine to treat chicken affected by diseases. Different methods were mentioned as traditionally used 
Table 1. Major causes of chicken mortality above the age of 7 days.

\begin{tabular}{lcc}
\hline Causes of mortality & Frequency & Percentage \\
\hline Disease & 156 & 86.4 \\
Predation & 165 & 91.9 \\
Bad weather & 1 & 0.6 \\
Mismanagement & 1 & 0.6 \\
\hline
\end{tabular}

Table 2. Causes for chick mortality in the selected households in the study areas.

\begin{tabular}{lcc}
\hline Causes & Frequency & Percentage \\
\hline Miss management & 53 & 29.4 \\
Predation & 122 & 67.8 \\
Disease & 10 & 5.6 \\
Bad weather & 11 & 6.1 \\
Cold & 10 & 5.6 \\
Hot & 1 & 0.6 \\
Cannibalism & 1 & 0.6 \\
Low mothering ability & 6 & 3.3 \\
Not known & 6 & 3.3 \\
\hline
\end{tabular}

Table 3. Signs and diseases noticed as causes of mortality in chicken in the study areas.

\begin{tabular}{lcc}
\hline Sign of disease or names of known disease & Frequency & Percentage \\
\hline Depression and death within 3 days & 87 & 48.4 \\
Diarrhea & 118 & 65.6 \\
Blackening of comb & 21 & 11.7 \\
Loss of appetite & 15 & 8.3 \\
Eye swelling and blinding & 21 & 11.7 \\
Coughing and sneezing & 17 & 9.4 \\
Paralyzed & 6 & 3.3 \\
Staggering movement & 9 & 5 \\
Lowering of the head down & 52 & 28.9 \\
Twisting of the neck & 1 & 0.6 \\
Newcastle disease (Fengel) & 130 & 72.2 \\
Fowl Pox (Fentata) & 1 & 0.6 \\
Gumboro Disease & 1 & 0.6 \\
Mites & 20 & 11.1 \\
\hline
\end{tabular}

medicines for diseases of chicken (Table 5). The traditional medicaments are usually mixed with feed specially Injera (type of food from Eragrostis teff) and fed to sick birds. Except for gas oil and Otostegia interifolia smoking, which are used against external parasites, all the others are used to all health problems of chicken.

When farmers get replacement flock (new) from other source, $64.5 \%(n=116)$ respondents check the health status of chicken by visual observation. The criteria used to determine the health status of chicken while acquired were alertness and the nature of feces at the vent area.
There were also some respondents restricting movement of chicken during disease outbreaks (13.9\%) $(n=25)$.

The ways of disposal of the bodies of dead chicken by sampled households include throwing away in the field $(62.2 \%)(n=112)$, burying $(18.9 \%)(n=34)$, throwing in the toilet $(1.1 \%)(n=2)$ and burning $(1.1 \%)(n=2)$. Most of the farmers $(87.2 \%)(n=157)$ were not aware of means of disease transmission. Dog was incriminated as a means of disease transmitter by $6.7 \%(n=12)$ of the respondents. The remaining $6.1 \%(n=11)$ of the sampled 
Table 4. Predators causing loss of chicken in the selected households in the study areas.

\begin{tabular}{lccl}
\hline Predators & Frequency & Percent & Age group affected \\
\hline Vultures & 117 & 65 & Chicks \\
Mongoose & 77 & 42.8 & All age groups \\
Wild cat & 16 & 8.9 & All age groups \\
Home Cat & 128 & 71.1 & Chicks \\
Dog & 25 & 13.9 & Mostly chicks \\
Mouse & 6 & 3.3 & Chicks \\
Other birds & 5 & 2.8 & Chicks \\
\hline
\end{tabular}

Table 5. Methods used for traditional treatment of sick chicken in the study area.

\begin{tabular}{ll}
\hline Category & Traditional medicaments \\
\hline \multirow{3}{*}{ Liquid } & Local alcoholic drink (Areke) \\
& Food oil \\
& Gas oil \\
& Senafech (Brassica japonica) \\
& Hot pepper (Capsicum frutescens) \\
Spices & Hyena onion (Dipcadi lanceolatum) \\
& Garlic (Allium sativum) \\
& Feto (Lepidium sativum) \\
& Common salt \\
& Sensel (Adathoda schimpriana) \\
& Rete (Aloe trichocantha) \\
& Lemon (Citrus aurantifolia) \\
& Citrus aurantium \\
& Eucalyptus globulus \\
& Kil (Lagenaria siceraria) \\
& Melya (Melia azedarach) \\
& Tenejute (Otostegia interifolia) \\
& Gerwa (Vernonia amygdalina) \\
& Kurkura (Zizyphus spina-christ) \\
& Holy powder (Emenete) \\
& Cutting of black combs
\end{tabular}

households considered bodies of dead chicken as potential sources of diseases.

\section{Predation control}

About $50.6 \%$ ( $n=91)$ of the respondents did not have any measure to control predation, $1.7 \%(n=3)$ plant tree to control predators specially vultures, $5.6 \%(n=10)$ of them predate predators by themselves and $19.4 \%(n=$ 35) used dogs to predate predators. Confining chickens specially during night time was also one option to cope with the problem of predators for $19.4 \%(n=35)$ of the respondents. Some of the respondents $(3.3 \%)(n=6)$ used toxic chemical to kill the predators.

\section{Controlling bad weather}

Of the total respondents, $65.6 \%(n=118)$ did not take any measure to reduce the impact of the bad weather and $17.2 \%(n=31)$ confined chicks until the weather gets better (warm). About $4.4 \%(n=8)$ of the respondents adjust hatching time at dry season to reduce the negative effect of cold weather while $12.2 \%(n=22)$ supply heat for chicks by using straw and reduce heat loss by putting chicks in an enclosure locally called Debegnete (locally material which is made from soil and teff straw to supply heat for chicks).

\section{DISCUSSION}

The overall mean of chicken flock for smallholder farmers was 9.17. The mean disposal number is higher than the increment number. The higher disposal of chicken was in relation to mismanagement, disease, predation, bad weather and sell and slaughter; from these disease and predation contribute the higher proportion for the higher rate of disposal of chickens. Different authors also confirmed this result (Tadelle, 1996; Tadelle and Ogle, 2001).

This result showed that mortality of chicks less than 7 days was mainly due to mismanagement and predation problems. This result disagrees with the findings of Tadelle and Ogle (2001) who reported disease as the most important factor in the death of chicks in the first 2 months of their life. This difference could be due to the long age range considered by the authors. On the other hand, Kitalyi (1998), Tadelle and Ogle (2001) and Udo et al. (2006) emphasized that mortality during brooding stage was high for village chickens. Mismanagement in the form of poor housing, poor hygiene and inadequate feeding predisposes bird to diseases, predators and other miscellaneous consequences including accidents and poisoning.

In the group of chicken which were above 7 days old, the causes of mortality were the same as those chickens which were less than 7 days old. However, the most important causes were predation and disease. Predation and diseases were identified as major constraints by different authors (Sonaiya, 1990; Spradbrow, 1994; 
Kitalyi, 1997; Mapiye and Sibanda, 2005; Udo et al., 2006; Dinka et al., 2010). The fact that predation and disease were the most important causes of chicken mortality in this study is an indication that village chickens are not protected from diseases and predation due to reasons like lack of awareness, lack or improper housing and economic incapability.

Mostly the farmers indicated that they simply throw away the dead body of the birds in the field and this might also create a good ground for disease transmission. Different report also confirmed that dead birds not properly disposed, pose a danger to other flocks and farms and cause soil, air and water pollution (Prabakaran, 2003; Mammo, 2006).

Among the diseases mentioned as important by respondents in the current study, NCD was cited as the most serious. This finding agrees with the reports of Gueye (1998) and Aboe et al. (2006). The majority of the household indicated that disease occurrence is higher at long and short rainy seasons. This is supported by the report of Mapiye and Sibanda (2005) who indicated that diseases and parasites contributed markedly to high flock mortalities recorded during the rainy season. This is because the conditions promote vector survival and multiplication and lowers bird's resistance to infection and infestation.

Traditional medicine made from different plants, spices and others materials, were used in the study area to control disease problems. In addition, some respondents try to control the disease occurrence by buying replacement flock from known person mostly in the village. These practices were also reported by Tadelle and Ogle (2001) and Tadelle (1996). It would appear that simple changes in management practices (e.g. preferential provision of feed to newly hatched chicks), home remedies (e.g. indoor management of chicks) and including attention to small details (e.g. control of predators) are believed to be capable of significantly reducing losses and in turn improve the off take rate from traditional chicken farming (Tadelle et al., 2003b).

Flying predators like vulture and other birds were among the predators most frequently mentioned by the respondents in this study. This was also indicated by Biswas et al. (2008).

Even if the problem of predation is serious, about half of the respondents indicated that they did not take any measure to control this problem. The remaining group practiced confinement of birds during night period, kept dogs around rearing areas to predate predators and kill predators by toxic substance. The predators might also be prevented by putting simple fencing made from materials like sticks around the rearing places. To prevent chicken from nocturnal predators, a smallholder should keep chickens in a well-constructed night-shelter made from stronger wood (Biswas et al., 2008).

Although bad weather was not a common problem in this study, whenever, the problem comes, farmers in this study tended to control effects of cold weather by confining chicks in a locally made pot (debegnet) until the weather improves. This practice is in line with the report of Tadelle and Ogle (2001).

\section{CONCLUSIONS AND RECOMMENDATIONS}

The chicken flock dynamics is mainly a function of hatching and purchasing for flock increment and mortality and sales for disposals. The most important causes of chicken mortality were predation, disease and mismanagement. Farmers used different strategies to control the effects of disease and predation including the use of traditional medicine against diseases and planting of tree, predation of predators, use of toxic chemical to kill the predators and confinement of chickens specially during night time were used to some extent against predation.

Based on the results of this study, the following are recommended:

(1) Creation of awareness and training of farmers as to the importance of proper housing and good management should be carried out .

(2) Since traditional medicine was widely used by farmers, studies are needed to determine the efficacy and the exact medical value for specific poultry disease;

(3) More detailed studies should be carried out to investigate the disease problems prevailing in the study area that would help develop a sustainable strategy of disease prevention and control

\section{ACKNOWLEDGMENTS}

The authors would like to thank farmers for their cooperation for interview, and SIDA/SAREC and Addis Ababa University for their financial support of the research project.

\section{REFERENCES}

Aboe PAT, Boa-Amponsem K, Okantah SA, Butler EA, Dorward PT, Bryant MJ (2006). Free-range village chickens on the Accra Plains, Ghana: Their husbandry and productivity. Trop. Anim. Health Prod. 38: 235-248.

Ashenafi $\mathrm{H}$, Eshetu $\mathrm{Y}$ (2004). Study on gastrointestinal helminthes of local chickens in central Ethiopia. Revenue Med. Vet. 155:504-507.

Biswas PK, Uddin GMN, Barua H, Roy K, Biswas D, Ahad A, Debnath NC (2008). Survivability and causes of loss of broody-hen chicks on smallholder households in Bangladesh. Prev. Vet. Med. 83:260-271.

CACC (Central Agricultural Census Commission) (2003). Statistical report on farm management practices, livestock and farm managements. Central Statistical Authority report of 2004-2005, Vol. II, Addis Ababa, Ethiopia.

Copland JW, Alders RG (2005). The Australian village poultry development programme in Asia and Africa. World's Poult. Sci. J. 61:31-38.

CSA (Central Statistics Authority) (2009). Agricultural sample survey 2009/10. Report on livestock and livestock characteristics, 
2. Statistical Bulletin No. 468. Addis Ababa, Ethiopia.

Dinka H, Chala R, Dawo F, Bekana E, Leta S (2010). Major Constraints and Health Management of Village Poultry Production in Rift Valley of Oromia, Ethiopia. American-Eurasian J. Agric. Environ. Sci. 9:529533.

FAOSAT (2012). FAO Statistical Year Book 2012. FAO, Rome, Italy, Http://faostat.fao.org. Accessed May 10, 2013-05-10.

Gueye EF (1998). Village egg and Fowl Meat Production in Africa. World's Poult. Sci. J. 54:73-86.

ILCA (International Livestock Center for Africa) (1990). Livestock systems research manual. Vol.1. ILCA working Paper 1. ILCA, Addis Ababa, Ethiopia.

Kitalyi AJ (1997). Village chicken production systems in developing countries. What does the future hold? World Anim. Rev. 89:48-53.

Kitalyi AJ (1998). Village chicken production systems in rural Africa. Households food and gender issues. FAO Animal Production and Health Paper 142. Food and Agriculture Organization of the United Nations: Rome Italy.

Mammo M (2006). Survey on village chicken Production under Traditional Management Systems in Jamma Woreda, South Wollo, Ethiopia. M.Sc. Thesis Haramaya University, Ethiopia.

Mapiye C, Sibanda S (2005). Constraints and opportunities of village chicken production systems in the smallholder sector of Rushinga district of Zimbabwe. Livestock Research for Rural development 17:115.

ONRS (Oromia National Regional State) (2011). Ada'a Liben Woreda Profile.

http://www.oromiyaa.com/english/index.php?option=com content\&vie $\mathrm{W}=$ article\&id $=249 \&$ Itemid=514, Accessed May 10, 2013

Prabakaran R (2003). Good practices in planning and management of integrated commercial poultry production in South Asia. FAO Animal Production and Health Paper 159. Food and Agriculture Organization of the United Nations Rome.

Sonaiya EB (1990). The context and prospects for development of smallholder rural poultry in Africa. Proceedings CTA International Seminar on Smallholder Rural Poultry Production, Thessaloniki, pp. 35-52.

Spradbrow PB (1994). Newcastle disease in village chickens. Poultry Sci. Rev. 5:57-96.

Tadelle D (1996). Studies on village poultry production systems in the central highlands of Ethiopia. M.Sc. Thesis. Swedish University of Agriculture Sciences, Uppsala, Sweden.

Tadelle D, Ogle B (2001). Village poultry production systems in the central highlands of Ethiopia. Trop. Anim. Health Prod. 33:521-537.

Tadelle D, Kijora C, Peters KJ (2003a). Indigenous chicken ecotypes in Ethiopia: growth and feed utilization potentials. Int. J. Poult. Sci. 2:144-152.

Tadelle D, Million T, Alemu Y, Peters KJ (2003b). Village chicken production systems in Ethiopia: use patterns and performance valuation and chicken products and socio economic functions of chicken. Debre Zeit Agriculture Research Center, Debre Zeit, Ethiopia.

Tadesse G (2005). Investigations into Technical Interventions to Improve Rural Poultry Production Systems in South Wollo Zone. M.Sc. Thesis, Haramaya University, Ethiopia, Alemaya, Ethiopia.

Udo HMJ, Asgedom AH, Viets TC (2006). Modelling the impact of interventions in village poultry systems. Agric. Syst. 88:255-269. 